\title{
The Exploration and Research of Teaching Reform about "Database Theory and Applications"
}

\author{
Jia L $\ddot{U}^{*}$, Jianfeng Liu \\ College of Computer and Information Science of Chongqing Normal University, Chongqing 401331, China \\ *1vjiacqnu@126.com.
}

\begin{abstract}
According to the teaching process of "Database Theory and Applications", basic principle is boring, knowledge is tedious, the practical application is difficult, enthusiasm is not high, learning objectives are not clear. This paper proposed the three-dimensional teaching method which is based on project-driven to realize the creative education. Combined with social needs guidance, the school's location, leading and supporting role of teachers, and the students' subject status and subjective initiative, to solve the problems in the teaching process, improve student awareness of active learning, train students' quality thinking, enhance independent problem solving skills. Practice has proved that the teaching model proposed has achieved good results in the "principle and application of database teaching".
\end{abstract}

Index Terms - project driven, three-dimensional teaching, active learning, innovation education

\section{Introduction}

"Database Theory and Applications", which has the very strong practical and comprehensive, is an important required course of computer related professional[1], database technology has become one of the leading technology of computer information management. In the traditional teaching mode, the teaching has been in according to the theory of knowledge learning and students have been accept[2]. As the theoretical teaching aides, experimental teaching, the theory of the verifier[3] often plays a supporting role. This ignores the ability to design the experiment and the ability of independent innovation, affects the teaching quality of the course, results in both teaching and learning experience of this course abstract and boring.

In the traditional teaching mode, although the students can better grasp each course isolated knowledge, but their comprehensive ability, practical ability and development ability is very low, can not meet the demand of social development for database technology talents, which is one of the reasons of graduates employment.

In recent years, based on the situated cognition, constructivism, pragmatism, "learning by doing" as the basic theory of project driven teaching method is developing rapidly. These methods are mainly embodied in the project to guide the process of teaching and leading role, to guide the students how to learn, how to learn, what to learn, to guide the students to learn actively in terms of teaching "practice theory practice"[4].

According to the characteristics of College of computer training, Wang[3] proposed theory and practice to put forward project driven teaching, so that students can master the practical skills, enhance the competitive employment. Feng[5] proposed innovation education research, that the task driven combined with project driven, trying to break the single project driven, the extracurricular practice activities into the training system, and achieved certain results. Zhong[6]proposed, based on project driven teaching method, case teaching and team cooperation, to enable students to master the software development process of the system and lay a solid foundation for the future development of the system software. Based on project driven, Zhang[7]proposed teaching design should combine with questions and guide, training and practice the principle of combining, to enable students to master the basic method of program design, familiar with the development process.

Analysis of the above scholars, combining with the reality of our university, this paper puts forward based on project driven, combined with the actual needs of society for talents database technology, accurate positioning the direction of school development, exert teachers' leading and supporting role, fully affirmed the student main body status and initiative, the establishment of new teachers and students relations of cooperation.

\section{Three-Dimensional Teaching Method Based on Project Driven}

Database technology plays a very important role and has been the main courses of computer related fields[8], its basic theory especially the theory of relational database structure, system integrity and very practical, its basic teaching goal is to require students to palm grip design ability of database application system.

This paper puts forward a three-dimensional teaching method based on project driven, putting the social demand as the guidance, the premise of correct positioning in the school, exerting the teacher's leading position and a supporting role, promoting the cooperation between teachers and students[9], fully mobilize the initiative of students.

Take the social demand as the guidance. The final purpose of training talents in universities is to serve the society, to meet the needs of the society, so the social demand determines the training objectives, but also directly affect the employment rate of College graduates.

Based on project driven, teachers workload will increase, select moderate carefully difficulty, be able to fully integrate theory, meet the social needs of the project, and the project be ready to focus on knowledge-related fields. In 
the process of doing the project, the students and teachers give full play to the role of counseling, teachers answer difficult questions, regular inspection and supervision, to provide students with the theoretical and technical support.

Dominant position and initiative of students. Project driver is under the framework of the "discovery problem solving problems - access to knowledge", it has strong objective and pertinence, students should fully mobilize their own initiative.

\section{The Specific Implementation}

Based on project driven, teaching in practical implementation of three-dimensional teaching method of "Database Theory and Applications" are as follows.

\section{A. Preparation}

Selecting the project is the most important work of the Preparation. Project selection should follow closely combined with the theoretical principle, practical principle, comprehensive principle, practical principle.

\section{B. Implementation process}

Based on project driven three-dimensional teaching includes "according to the needs of society and school development positioning, teachers select the project", "teachers put the project into the class, analysis and decompose the project" and "students link theory and application and complete the project".

The first step, teachers should prepare and explain the course teaching plans and teaching goal, let the students know the goals and grasp what technology through the course. After the completion of the project, students can master SQL Server database management system each knowledge point and database technology development capabilities basically.

The second step, we take the data query and index data in this chapter as an example. First of all, teachers show this complete system to the students, then analyze the project and decompose tasks, including how to define the problem, such as the students basic information table, other curriculum subjects; how to solve problems, to enable students to identify between tables affiliation; how to guide students to discover the existence of non-relational data model problems.

Managing information more effectively is the main purpose of database technology. To complete the query operation, it must learn SQL Server language. Through the study of this chapter, students can completely understand basic syntax for the SELECT statement, single-table queries, multi-table query, the query interface of the learning operation.

The third step, the students study in the task driven. Design the relation database, learn SQL query SELECT statement. The query is an important part of database operations, SELECT statement can be used to complete the query operation data needed in the database. In addition to select, insert, delete and other basic operations, but also to learn other features, such as an assignment to a variable, the output value of the expression and so on.

The fourth step, the concept of the index is introduced in this chapter, teachers should play a supporting role, explain to the students how to build index, and the benefits of index, accelerate the retrieval of useful information on the content of many database, speed up the table connection, reduce the sorting and grouping of time, realize the complete reference table etc. Thus expands students' knowledge space.

Finally, complete the sub project of this chapter. Combined with the actual needs of the project, based on the problem driven, make the students feel the skills to use, based on results driven, lets the student feel success, enhance a sense of achievement and thirst for knowledge of the students.

\section{The Effect Evaluation of Teaching}

A new teaching methods should evaluate by the standard of teaching effect [14]. The evaluation includes two aspects of students and teachers. The final evaluation standard of computer specialty is to check whether the students have the thinking ability, ability of solving problem, innovation ability, cooperation ability of the team, software applications and development ability.

\section{A. Assessment of student achievement}

Teaching assessment is an important part of the process, it should persist encouraged principle, guiding principle and the feedback principle. The student achievement assessment of project driven three-dimensional teaching method should be different from the traditional teaching mode. Under the traditional teaching mode, students achievement evaluation includes three parts which are often the final exam score accounted for $60 \%$, experimental results for $20 \%$, peacetime result to account for $20 \%$. Score calculation method of teaching model proposed in this paper: item scores accounted for $50 \%$ (of which $30 \%$ completed projects, innovation projects accounted for $20 \%$ ), the theoretical results for $30 \%$, discussion class scores accounted for $20 \%$. From the calculation results of the weight, the biggest difference is the practical problem solving ability which was strengthened.

In addition, teachers should take the usual multiple achievements to assess student achievement, but not the final word, The teacher regularly check and supervise the schedule and the situation, timely feedback and assist them to finish the project.

\section{B. Evaluation of Teaching Ability}

In the new teaching mode, teacher's ability also need further improvement. It is vital to select the project, and we must seize this first step. To be further innovation in theory and learn from enterprise engineer, master leading technology.

Changing roles of teachers and students. Teachers change into a helper and students' partners from indoctrinate people. So the evaluation for teacher should be done from the quality of student projects, and student's cooperation 
ability, teaching ability, comprehensive assessment of spare time and students discuss and other aspects, and not be a single theory teaching.

In short, the evaluation criteria can not stay in a single, conservative, traditional model, but be a variety of effective, flexible evaluation methods. So that the new teaching model can adapt to the needs of the community college.

\section{Conclusions}

Based on the social needs of database of talents, starting from the three aspects of school, teacher and student, we proposed a teaching reform about "Database Theory and Applications", that is project driven three-dimensional teaching method, we made specific plans on how to implement and and illustrated. At last, the evaluation principle and evaluation standard are gave. In the future, we also need to consider the school's support, teachers' participation in enterprise training, the cooperation mode of teachers and students, the selection of project and project training environment. It is also worthy of study and exploration on extending to related disciplines and other colleges and universities.

\section{Acknowledgment}

The research work was supported by the key projects of teaching reform in university of Chongqing of China
(No.1202025). And Chongqing Education Science occupation education research project planning project of "Twelfth Five Year Plan"(2013-ZJ-050) in 2013 year

\section{References}

[1] Li Junshan, Luo Rong, Zhao Fangzhou. Principle and application of database. Tsinghua university press, 2009,6

[2] Yang Yuexin, Yang Yun. Study of the course teaching of "database principle and application". Education Teaching Forum, 2013, 23(1): 239-240.

[3] Wang Wen. Reform of teaching the course in project driven "Linux operating system". Computer Education, 2009, 18(9): 77-79

[4] Huang Minghe, Lei Gang, Guo Bin etc. Research and practice of "tutorial system project teaching model". Computer Education, 2007, 1(02): 29-31

[5] Feng Lin, Zheng Weiwei. Innovative education research on "task driving" combined with "project driven". Heilongjiang Education(Higher Educational Research and Evaluation), 2010, 4: 57-59

[6] Zhang Zhonglin. Based on project driven teaching reform of "software engineering" computer. Computer Education, 2002, 2(02): 53-55

[7] Zhang Chunying, Liu Fengchun. Research on Visual Basic programming teaching model based on project development. Computer Education, 2010, 3(05): 105-107

[8] Gu Bing. Technique and application of database. Tsinghua university press, 2010.2

[9] Hu Zhaobing, Zhang Xingyu. Cooperative learning on the exploration of teaching reform to improve teaching effect. Journal of Chongqing Normal University: Natural Science Edition, 2008, 25(4): 102-105 